\title{
Risk factors of severe hypoglycaemia in adult patients with Type I diabetes - a prospective population based study
}

\author{
I. Mühlhauser, H. Overmann, R. Bender, U. Bott, M. Berger \\ Department of Nutrition and Metabolic Diseases (WHO-Collaborating Centre for Diabetes), \\ Heinrich-Heine University, Düsseldorf, Germany
}

\begin{abstract}
Summary The objective of this study was to identify possible risk factors of severe hypoglycaemia $(\mathrm{SH})$ in a prospective population based study of adult Type I (insulin-dependent) diabetic patients. A representative sample of 684 patients ( $41 \%$ women, mean \pm SD age $36 \pm 11$, diabetes duration $18 \pm 11$ years), living in the district of Northrhine (9.5 million inhabitants), Germany, were examined in their homes using a mobile ambulance. A comprehensive baseline assessment of possible predictors of SH included sociodemographic and disease related variables, hypoglycaemia awareness, diabetes management, and attitudes and behavioural aspects as expressed by the patients. After a mean of $19 \pm 6$ months $669(98 \%)$ patients were interviewed about events of $\mathrm{SH}$ since the baseline examination. Using the multiple Cox proportional hazards model, five risk factors of SH were identified: SH during the preceding year [hazard ratio (HR) 2.7, $95 \%$ confidence intervals (CI) 1.8-4.2], any history of SH (HR 1.9, CI 1.1-3.4), C-peptide negativity (HR
\end{abstract}

4.0, CI 1.2-12.7), social status (HR 0.8 for a difference of 5 units for a value range of 0-24, CI 0.6-0.9), and patients' determination to reach normoglycaemia (HR 0.7 for a difference of 1 unit for a value range of $1-6$, CI 0.5-0.9), indicating that the lower the social status and the higher the patients' determination to reach normoglycaemia, the higher the risk of SH. After eliminating the history of hypoglycaemia from the model, impaired hypoglycaemia awareness and patients' inappropriate denial of $\mathrm{SH}$ as their particular problem became additional significant risk factors of SH. In conclusion, in this population based study of adult Type I diabetic patients, C-peptide negativity, a previous event of SH, patients' determination to reach normoglycaemia and social class were risk factors of SH. [Diabetologia (1998) 41:1274-1282]

Keywords Type I diabetes, severe hypoglycaemia, risk factors, hypoglycaemia awareness, patient education, social class, behaviour, attitude, C-peptide.
Identification of risk factors of severe hypoglycaemia (SH) is necessary to understand, predict and reduce the frequency of SH in Type I (insulin-dependent) diabetic patients. Several predictors of $\mathrm{SH}$ have been

Received: 14 November 1997 and in revised form: 20 April 1998

Corresponding author: Univ.-Prof. Dr. med. Ingrid Mühlhauser, Klinik für Stoffwechselkrankheiten und Ernährung, Heinrich-Heine Universität Düsseldorf, Moorenstrasse 5, D-40225 Düsseldorf, Germany

Abbreviations: SH, severe hypoglycaemia; HR, hazard ratio; CI, confidence interval; DTTP, structured diabetes treatment and teaching programme; CSII, continuous subcutaneous insulin infusion; DCCT, Diabetes Control and Complications Trial. described in laboratory and clinical investigations. The most consistently identified risk factor is a previous event of SH [1-3]. Less consistent predictors of $\mathrm{SH}$ are lower $\mathrm{HbA}_{1 \mathrm{c}}$ values, higher insulin dosages, C-peptide negativity, and longer diabetes duration [1-5]. Patients with impaired awareness of hypoglycaemia could run a particularly high risk of SH [5-7]. Several clinical conditions predispose to $\mathrm{SH}$ such as renal insufficiency and early pregnancy $[8,9]$.

In the intensively treated patients of the Diabetes Control and Complications Trial (DCCT), however, less than $8 \%$ of the variation in $\mathrm{SH}$ could be explained by biological characteristics including $\mathrm{HbA}_{1 \mathrm{c}}$ values [2]. Recently, a bio-psycho-behavioural model was proposed to integrate the diverse and complex 
biological, psychological and behavioural processes that contribute to the development of SH in Type I diabetic patients [10]. So far, large clinical trials have not considered hypoglycaemia awareness or behavioural factors.

Observations made in experimental or clinical studies including selected patients of tertiary care centres might be of limited relevance for the general population of patients with Type I diabetes. So far, there are no studies on the risk of $\mathrm{SH}$ in representative groups of patients with Type I diabetes. In this prospective study, a comprehensive assessment of possible risk factors of SH was done in a population based sample of adults with Type I diabetes.

\section{Subjects and methods}

This study is a prospective extension of a previous populationbased survey of Type I diabetes with the objective to assess the quality of diabetes care achieved at the community level [11]. Detailed descriptions of the study protocol including recruitment criteria of physicians and patients, participation rate, and description of drop outs were published [11, 12]. In short, between November 1994 and July 1996 adult patients with Type I diabetes were recruited from a random sample of 630 family physician practices in the district of Northrhine ( $~ 9.5$ million inhabitants), Germany. Inclusion criteria for patients were: age 18 years or older and initiation of insulin therapy before 31 years of age. Of the 932 patients fulfilling the inclusion criteria $684(73 \%)$ participated in the study. The examinations were carried out in a mobile ambulance as described [11] by two of the authors (I.M. and H.O.) and, on occasion, by other trained investigators. Immobile patients were examined in their homes.

The examination protocol used an extended and adapted version of evaluation protocols as in previous studies and is available on request from the authors. The examination comprised a structured interview, questionnaires to be filled in by the patients, physical examination, fundus photography, and laboratory tests. The interview included questions assessing participant characteristics, such as sociodemographic and health status information, diabetes care and self-management across multiple areas and potential social, behavioural, and health care provider related correlates of self-management.

Classification of social status was based on instruments used in previous health surveys in Germany [11]. The social class score was an additive variable of the highest educational level achieved (scores 0-8), the present or last employment level (scores 0-8) and household income (scores 0-8) adding up to a score between 0 and 24; higher scores indicating higher levels of social class. For descriptive purposes quintiles of the total score were used to divide the patient group into five levels of social class (level I corresponding to the highest and level $\mathrm{V}$ to the lowest social class).

A self-administered questionnaire was used in order to assess patients' treatment goals [13]. The instrument consisted of 10 items which were rated on a 6-point Likert scale $(1=$ very important; $6=$ totally unimportant $)$. In the present study, five questions possibly relevant for the prediction of $\mathrm{SH}$ were used. These questions asked to what extent patients found it important that: 1) their blood glucose values were always $7.8 \mathrm{mmol} / \mathrm{l}$ or less; 2) their blood glucose values were as constant as possible; 3 ) they could avoid even mild hypoglycae- mia; 4) they could in any case avoid SH with loss of consciousness; 5) they had to measure their blood glucose as rarely as possible.

$\mathrm{HbA}_{1 \mathrm{c}}$ was measured by the Diamat HPLC-method (Biorad, Munich, Germany) (reference range 4.3\%-6.1\%). Random C-peptide concentrations were measured using a human C-peptide assay (Behring, Marburg, Germany). A value of less than $0.1 \mathrm{nmol} / 1$ was considered negative.

Accuracy of blood glucose self-measurements was assessed by comparing the value obtained by the patient using his own method with the laboratory measurement using Reflotron (Boehringer-Mannheim, Mannheim, Germany). A difference of $20 \%$ or less between the two results was considered acceptable.

For baseline evaluation of risk factors of $\mathrm{SH}$ a protocol was used, which was based upon previously used questionnaires [3, $7,14]$ and in part derived from experience by clinical experts caring for patients with intensified insulin therapy. Patients were asked the following questions:

1) "How many hypoglycaemic reactions did you have last week (exactly 7 days)?" Patients with more than two were considered at risk.

2) "How many blood glucose values did you measure last week that were less than $3.3 \mathrm{mmol} / \mathrm{l}$ ?" Patients with more than two (or patients who did not do any blood glucose measurements) were considered at risk. In addition, if there were more measurements of blood glucose values less than $3.3 \mathrm{mmol} / \mathrm{l}$ than the number of reported mild hypoglycaemias (question 1), patients were considered at risk.

3) "Do you recognize your hypoglycaemias in time to be able to help yourself (without assistance of another person)?" Possible answers were: a) yes, always (score 0); b) yes, most of the time (score 1); c) yes, during daytime, but not always during the night (score 2); d) no, often not (score 3); e) no, never (score 4). Patients who scored more than 1 were considered at risk.

4) "At what blood glucose value do you start to feel the first hypoglycaemic symptoms?" (referring to preceding weeks, patients were asked to indicate one figure, even if it was just an average of varying blood glucose values); scores 0 to 3 , respectively, for values a) $\geq 2.8 \mathrm{mmol} / \mathrm{l}$, b) $2.2-2.7 \mathrm{mmol} / \mathrm{l}$, c) less than $2.2 \mathrm{mmol} / \mathrm{l}$, d) never feeling symptoms. Patients who scored more than 0 were considered at risk.

Questions 3 and 4 were combined to construe a hypoglycaemia awareness score. The score ranges from 0 (fully aware) to 4 (fully unaware) (question 3: answers a) or b) scored 0, c) scored 1, and d) or e) scored 2; question 4: answers a) scored $0, \mathrm{~b}$ ) scored 1 , and c) or d) scored 2).

5) "Did you ever have a hypoglycaemic reaction in which you were unable to help yourself?" "If yes, how many of such hypoglycaemic reactions did you have during the last 12 months?" Patients who scored more than 0 were considered at risk.

6) "Did you ever have a hypoglycaemic reaction in which you were unable to help yourself and hypoglycaemia was treated by glucagon injection or glucose injection by a relative or physician?" "If yes, how many of such hypoglycaemic reactions did you have during the last 12 months?" Patients who scored more than 0 were considered at risk.

7) Patients were asked whether they had ever observed hypoglycaemic symptoms disappear without any intervention (score 2) and what they would do if hypoglycaemic symptoms appeared $10 \mathrm{~min}$ before lunch; if they would not immediately take carbohydrates, they scored 1 ; and if they would always immediately take additional carbohydrates they scored 0 . Patients who scored more than 0 were considered at risk. 
Table 1. Baseline data of the study population and incidence of SH (treated with glucagon or glucose injection) during follow-up for the respective subgroups

\begin{tabular}{|c|c|c|}
\hline & $\begin{array}{l}\text { mean }(\mathrm{SD}), \\
\text { range or } n(\%) \\
\text { patients }\end{array}$ & $\begin{array}{l}\mathrm{SH}^{\mathrm{a}} \text { during } \\
19 \text { months fol- } \\
\text { low-up (events } \\
\text { per patient) }\end{array}$ \\
\hline Number of patients & $669(100)$ & 0.31 \\
\hline $\begin{array}{l}\text { Sex } \\
\text { women } \\
\text { men }\end{array}$ & $\begin{array}{l}277(41) \\
392(59)\end{array}$ & $\begin{array}{l}0.35 \\
0.29\end{array}$ \\
\hline Age (years) & $\begin{array}{l}36(11) \\
18-77\end{array}$ & - \\
\hline Diabetes duration (years) & $\begin{array}{r}18(11), \\
0.3-55\end{array}$ & - \\
\hline $\begin{array}{l}\leq 20 \text { years } \\
>20 \text { years }\end{array}$ & $\begin{array}{l}405(61) \\
264(39)\end{array}$ & $\begin{array}{l}0.26 \\
0.38\end{array}$ \\
\hline Body mass index $\left(\mathrm{kg} \cdot \mathrm{m}^{-2}\right)$ & $\begin{array}{l}24.6(3.4), \\
16.4-43.4\end{array}$ & - \\
\hline $\begin{array}{l}\text { Social class } \\
\text { I (highest) } \\
\text { II } \\
\text { III } \\
\text { IV } \\
\text { V (lowest) }\end{array}$ & $\begin{array}{l}130(19) \\
138(21) \\
134(20) \\
141(21) \\
126(19)\end{array}$ & $\begin{array}{l}0.20 \\
0.20 \\
0.31 \\
0.33 \\
0.53\end{array}$ \\
\hline $\begin{array}{l}\text { C -peptide } \\
\text { negative } \\
\text { positive }\end{array}$ & $\begin{array}{r}570(87) \\
83(13)\end{array}$ & $\begin{array}{l}0.35 \\
0.06\end{array}$ \\
\hline $\begin{array}{c}\mathrm{HbA}_{1 \mathrm{c}}(\%) \\
\leq 7.0 \\
>7.0\end{array}$ & $\begin{aligned} 8.0(1.5) \\
4.5-12.8 \\
183(27) \\
485(73)\end{aligned}$ & $\begin{array}{l}0.42 \\
0.27\end{array}$ \\
\hline $\begin{array}{l}\text { Insulin dosage } \\
\left(\begin{array}{l}\left.\mathrm{U} \cdot \mathrm{kg}^{-1} \cdot \mathrm{day}^{-1}\right) \\
\quad \leq 0.8 \\
\quad>0.8\end{array}\right.\end{array}$ & $\begin{array}{l}\quad 0.65(0.21) \\
0-1.87 \\
540(81) \\
129(19)\end{array}$ & $\begin{array}{l}0.29 \\
0.40\end{array}$ \\
\hline $\begin{array}{l}\text { Insulin injections per day (\%) } \\
\quad \leq 2 \\
>2 \\
\text { CSII }\end{array}$ & $\begin{array}{c}137(21) \\
470(70) \\
62(9)\end{array}$ & $\begin{array}{l}0.26 \\
0.33 \\
0.31\end{array}$ \\
\hline $\begin{array}{l}\text { Blood glucose self-monitori } \\
\text { per day } \\
\quad<2 \\
\quad \geq 2\end{array}$ & $\begin{array}{l}102(15) \\
567(85)\end{array}$ & $\begin{array}{l}0.20 \\
0.33\end{array}$ \\
\hline $\begin{array}{l}\text { Following a meal plan } \\
\text { yes } \\
\text { no }\end{array}$ & $\begin{array}{l}195(29) \\
474(71)\end{array}$ & $\begin{array}{l}0.41 \\
0.27\end{array}$ \\
\hline $\begin{array}{l}\text { Carbohydrate counting } \\
\text { yes } \\
\text { no }\end{array}$ & $\begin{array}{r}557(86) \\
97(14)\end{array}$ & $\begin{array}{l}0.32 \\
0.29\end{array}$ \\
\hline
\end{tabular}

Insulin dose adaptation on a day-to-day basis according to blood glucose values

$\begin{array}{lll}\text { yes } & 522(78) & 0.33 \\ \text { no } & 146(12) & 0.24\end{array}$

Insulin dose adaptation on a day-to-day basis according to carbohydrate intake

$\begin{array}{lll}\text { yes } & 416(62) & 0.29 \\ \text { no } & 252(38) & 0.35\end{array}$

Alcohol consumption (g/week) $\begin{array}{lll}\leq 70 & 529(79) & 0.33\end{array}$ $\begin{array}{lll}>70 & 139(21) & 0.25\end{array}$

Regular sports activities (hours/week) $\begin{array}{lll}\geq 1 & 293(44) & 0.29 \\ 0 & 376(56) & 0.33\end{array}$

\begin{tabular}{lll}
\hline & $\begin{array}{l}\text { mean (SD), } \\
\text { range or } n(\%) \\
\text { patients }\end{array}$ & $\begin{array}{l}\text { SH during } \\
19 \text { months fol- } \\
\text { low-up (events } \\
\text { per patient) }\end{array}$ \\
\hline $\begin{array}{l}\text { Smoking } \\
\quad \text { yes }\end{array}$ & $263(40)$ & 0.33 \\
$\quad$ no & $406(60)$ & 0.30 \\
$\begin{array}{l}\text { Participation in a DTTP } \\
\quad \text { yes }\end{array}$ & $415(62)$ & 0.35 \\
$\quad$ no & $254(38)$ & 0.25 \\
$\begin{array}{l}\text { Specialized out-patient care } \\
\text { last year }\end{array}$ & & \\
$\quad$ yes & $171(26)$ & 0.40 \\
$\quad$ no & $498(74)$ & 0.28 \\
$\begin{array}{l}\text { Renal insufficiency } \\
\text { yes }\end{array}$ & $31(5)$ & 0.23 \\
no & $637(95)$ & 0.32 \\
Pregnancy & & \\
$\quad$ yes & $6(1)$ & 1.5 \\
$\quad$ no & $663(99)$ & 0.30 \\
\hline
\end{tabular}

a $\mathrm{SH}=$ severe hypoglycaemia treated with glucagon or glucose injection

8) Patients were asked to show what they carried for the treatment of hypoglycaemic reactions; scores 0 to 2, respectively, for a) adequate type and amounts of carbohydrates; b) less adequate carbohydrates; c) nothing or inadequate carbohydrates. Patients who scored more than 0 were considered at risk. 9) Patients were asked how seriously they rated the problem of SH compared with their other diabetes related problems. Possible answers: a) it is no problem at all (score 0), there are bigger problems (score 1), it is a considerable problem (score 2), it is the biggest problem (score 3). Patients who had SH during the preceding year and scored 0 or 1 were considered at risk (denial of hypoglycaemia problem).

Follow-up study. Between February 1997 and June 1997 patients received a questionnaire on the frequency of hypoglycaemic reactions treated by glucagon injection or glucose injection by a relative or physician since the baseline examination. Patients were asked to state the date (month, year) for each hypoglycaemic event. Patients who did not return the questionnaire in time or who did not give complete or clear answers were contacted by telephone.

Statistical analysis. The Cox proportional hazards model [15] was applied to investigate the effects of a number of explanatory variables on the risk of hypoglycaemia. The time up to the first event of hypoglycaemia was used as response. Backward selection was used to identify the most important risk factors. The significance level for removing an explanatory variable from the model in the backward selection procedure was chosen as $\alpha=0.10$. Two different analyses were done: one including and one excluding the hypoglycaemia history of the patients, yielding two different final models. Adjusted hazard ratios (HRs) were calculated based upon the final models. The proportional hazards assumption was checked by plotting the $\log$ of the negative $\log$ of the estimated survival functions against log time and by including time-dependent covariates. To assess the ability of the Cox models to predict whether an individual will experience hypoglycaemia or not, measures for explained variation were calculated. To compare our results with those of the DCCT [2], the entropy $R^{2}[2,16]$ was used. As the entropy $R^{2}$ is inadequate to describe explained varia- 
Table 2. History of SH and incidence of SH (treated with glucagon or glucose injection) during follow-up for the respective subgroups

\begin{tabular}{|c|c|c|}
\hline & $\begin{array}{l}\text { Baseline } \\
n(\%)\end{array}$ & $\begin{array}{l}\mathrm{SH}^{\mathrm{a}} \text { during } \\
19 \text { months fol- } \\
\text { low-up (events } \\
\text { per patient) }\end{array}$ \\
\hline All patients & $669(100)$ & 0.31 \\
\hline \multicolumn{3}{|c|}{ Hypoglycaemia necessitating assistance } \\
\hline \multicolumn{3}{|l|}{ At any time } \\
\hline patients with no event & $263(39)$ & 0.11 \\
\hline patients with $>0$ events & $406(61)$ & 0.44 \\
\hline \multicolumn{3}{|l|}{ During preceding 12 months } \\
\hline patients with no event & $538(81)$ & 0.19 \\
\hline patients with $>0$ events & 130 (19) & 0.82 \\
\hline \multicolumn{3}{|c|}{ Hypoglycaemia treated with glucagon or glucose injection } \\
\hline \multicolumn{3}{|l|}{ At any time } \\
\hline patients with no event & $350(52)$ & 0.17 \\
\hline patients with $>0$ events & $319(48)$ & 0.46 \\
\hline \multicolumn{3}{|l|}{ During preceding 12 months } \\
\hline patients with no event & $583(87)$ & 0.23 \\
\hline patients with $>0$ events & $86(13)$ & 0.85 \\
\hline Incidence (events/patient year) & 0.21 & 0.20 \\
\hline
\end{tabular}

$\overline{\mathrm{SH}}=$ severe hypoglycaemia treated with glucagon or glucose injection

tion in survival analyses because of its values being too low [17], the likelihood ratio $R^{2}[18,19]$ was also calculated. For the calculation of the likelihood ratio $R^{2}$ values the total sample size was used as $n$ in the corresponding formula, because this measure was recommended for use in Cox models [20]. To describe the impact of the risk factors on the risk of hypoglycaemia the failure probability of having hypoglycaemia within 12 months was calculated for some exemplary risk profiles as 1-S $(t \mid x)$, where $\mathrm{S}(t \mid x)=\mathrm{S}_{0}(\mathrm{t})^{\exp \left(\beta^{\prime} \mathrm{x}\right)}$ is the conditional survival probability at time $(t)$ for an individual with covariate values $x, \beta$ is the vector of regression coefficients, and $\mathrm{S}_{0}(t)$ is the baseline survival function estimated by a nonparametric maximum likelihood method. For calculations the SAS procedure PHREG was used [21]. All tests were two-tailed. A $p$-value $<0.05$ was regarded as significant.

\section{Results}

Results of the baseline examinations are published elsewhere [11]. Of the 684 patients 352 returned the filled-in questionnaire, 317 were interviewed by telephone, 8 patients had died and 7 could not be contacted during the study period. Thus, complete follow-up data were available for 669 (98\%) of the original cohort. Baseline data of these 669 patients are summarized in Table 1.

The mean follow-up period was 19 months (range $7-30$ ). Of the 669 patients 100 reported a total of 208 events of SH (incidence 0.20 cases per patient year); 50 patients reported 1 event, 25 patients 2 events, and 25 patients 3 or more events. Descriptive data on the history of SH and the results of its occurrence during follow-up for the respective subgroups are summarized in Table 2. Tables 3 and 4 summarize re-
Table 3. Frequency of mild hypoglycaemia and hypoglycaemia awareness at baseline and incidence of SH (treated with glucagon or glucose injection) during follow-up for the respective subgroups

\begin{tabular}{|c|c|c|}
\hline & $\begin{array}{l}\text { Baseline } \\
n(\%)\end{array}$ & $\begin{array}{l}\mathrm{SH}^{\mathrm{a}} \text { during } \\
19 \text { months fol- } \\
\text { low-up (events } \\
\text { per patient) }\end{array}$ \\
\hline All patients & $669(100)$ & 0.31 \\
\hline \multicolumn{3}{|c|}{ Mild hypoglycaemia during preceding week } \\
\hline 0 & $230(34)$ & 0.25 \\
\hline $1-2$ & $267(40)$ & 0.35 \\
\hline$>2$ & $172(26)$ & 0.34 \\
\hline \multicolumn{3}{|c|}{ Number of blood glucose values $<3.3 \mathrm{mmol} / \mathrm{l}$} \\
\hline 0 & $256(38)$ & 0.22 \\
\hline $1-2$ & $211(32)$ & 0.34 \\
\hline$>2$ & $202(30)$ & 0.39 \\
\hline \multicolumn{3}{|c|}{$\begin{array}{l}\text { Reported number lower than number of glucose values } \\
<3.3 \mathrm{mmol} / 1\end{array}$} \\
\hline no & $488(73)$ & 0.30 \\
\hline yes & $181(27)$ & 0.33 \\
\hline \multicolumn{3}{|l|}{ Hypoglycaemia awareness } \\
\hline \multicolumn{3}{|c|}{ Recognizing hypoglycaemia in time } \\
\hline yes, always & $379(58)$ & 0.20 \\
\hline $\begin{array}{l}\text { yes, most of the time } \\
\text { yes, during daytime, but }\end{array}$ & $168(26)$ & 0.39 \\
\hline always during the night & $74(11)$ & 0.70 \\
\hline no, often not & $29(4)$ & 0.52 \\
\hline no, never & $7(1)$ & 0.29 \\
\hline \multicolumn{3}{|c|}{ Blood glucose values at which first symptoms are felt } \\
\hline$\geq 2.8 \mathrm{mmol} / 1$ & $423(66)$ & 0.25 \\
\hline $2.2-2.7 \mathrm{mmol} / 1$ & $132(20)$ & 0.34 \\
\hline$<2.2 \mathrm{mmol} / \mathrm{l}$ & $84(13)$ & 0.61 \\
\hline never feeling symptoms & $6(1)$ & 0.67 \\
\hline \multicolumn{3}{|c|}{ Hypoglycaemia awareness score } \\
\hline 0 (fully aware) & $312(47)$ & 0.17 \\
\hline 1 & $152(23)$ & 0.32 \\
\hline 2 & $104(16)$ & 0.44 \\
\hline 3 & $64(9)$ & 0.47 \\
\hline 4 (fully unaware) & $37(5)$ & 0.87 \\
\hline
\end{tabular}

${ }^{a} \mathrm{SH}=$ severe hypoglycaemia treated with glucagon or glucose injection

sults on the frequency of mild hypoglycaemia, hypoglycaemia awareness, and patients' attitudes and behaviour with respect to hypoglycaemia. Table 5 shows data for three treatment goals yielding relevant information.

We did two Cox regression analyses both starting with a backward selection. The first analysis contained the following variables: sex, age, body mass index, social class, diabetes duration, all variables derived from the hypoglycaemia questionnaire [13 variables], the five treatment goals, blood glucose selfmonitoring (score 0: patients who report to measure at least twice daily; score 1: patients who measure less often), accuracy of blood glucose monitoring [score 0: patients with accurate measurements; score 1: patients with inaccurate measurements or patients who did not carry out a blood glucose measurement in the mobile ambulance for one of the following reasons: patient does not perform blood glucose self- 
Table 4. Patients' attitudes and behaviour with respect to hypoglycaemia at baseline and incidence of SH (treated with glucagon or glucose injection) during follow-up for the respective subgroups

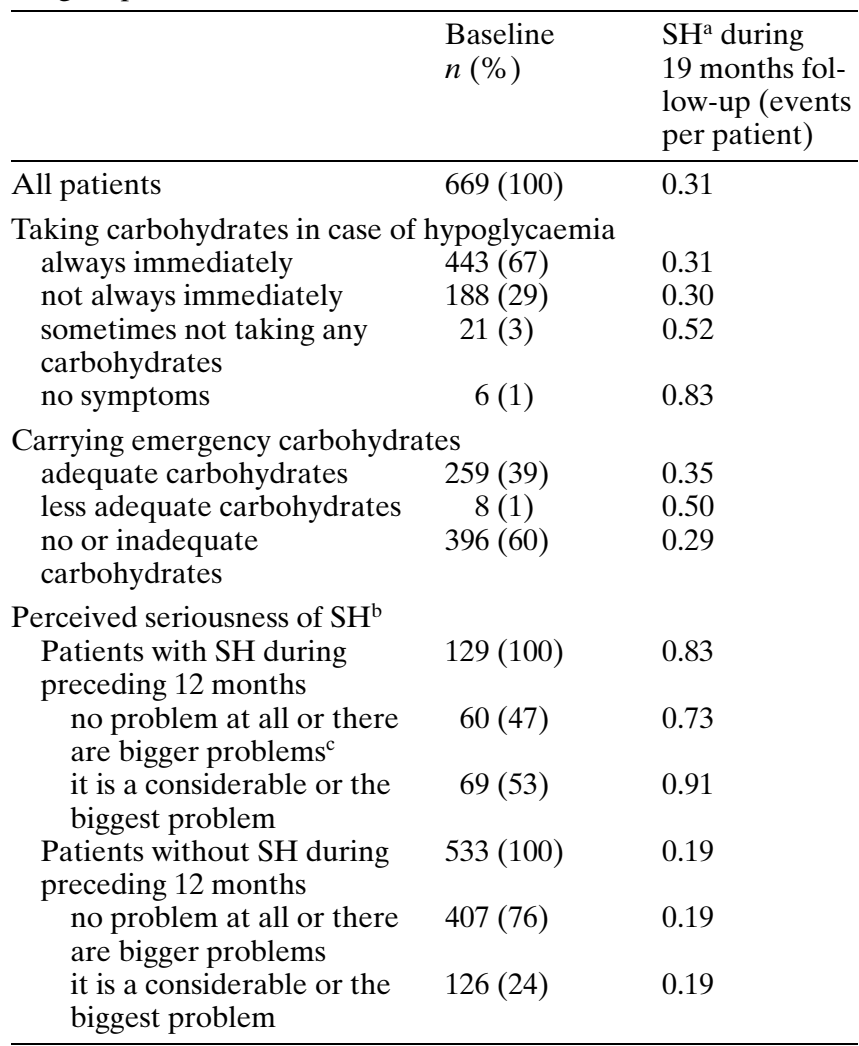

${ }^{a} \mathrm{SH}=$ severe hypoglycaemia treated with glucagon or glucose injection

${ }^{\mathrm{b}}$ severe hypoglycaemia necessitating assistance

${ }^{c}$ denial of severe hypoglycaemia as a problem

monitoring at all $(n=33)$, patient has not brought his materials for blood glucose monitoring although patients had been asked to do so $(n=54)$, the glucose meter did not work $(n=17)$, patient declined to do a blood glucose measurement $(n=9)$ ], consumption of alcohol (score 0: patients who reported to consume $70 \mathrm{~g}$ or less alcohol a week; score 1: patients who reported to consume more than $70 \mathrm{~g}$ alcohol per week), C-peptide (score 0: C-peptide positive $\geq 0.1$ nmol/l; score 1: C-peptide negative $<0.1 \mathrm{nmol} / \mathrm{l}$ ), $\mathrm{HbA}_{1 \mathrm{c}}(\%)$, nephropathy (score 0: normal serum-creatinine, no renal replacement therapy; score 1: serum creatinine $\geq 133 \mu \mathrm{mol} / 1$ or renal replacement therapy), insulin therapy (score 0: more than 2 insulin injections per day or CSII; score 1: 2 or less insulin injections per day), insulin dosage ( $\mathrm{U} \cdot \mathrm{kg}$ body weight $^{-1} \cdot$ day $^{-1}$ ), insulin dose adaptation on a day-today basis according to varying amounts of carbohydrate intake (score 0: adaptation; score 1: no adaptation), and previous participation in a structured diabetes treatment and teaching programme (DTTP) (score 0: patients have participated in a DTTP; score 1: never participated in a DTTP).
Table 5. Selected treatment goals at baseline and incidence of SH treated with glucagon or glucose injection during followup for the respective subgroups

\begin{tabular}{ll}
\hline Baseline & SH $^{\mathrm{a}}$ during \\
$n(\%)$ & 19 months fol- \\
& low-up (events \\
& per patient) \\
\hline
\end{tabular}

Blood glucose values always

$<7.8 \mathrm{mmol} / \mathrm{l}$

$\begin{array}{lrl}1 \text { (very important) } & 230(36) & 0.46 \\ 2 & 251(39) & 0.27 \\ 3 & 122(19) & 0.25 \\ 4 & 31(5) & 0.01 \\ 5 & 4 & 0 \\ 6 \text { (totally unimportant) } & 2 & 0 \\ \text { Avoiding even mild hypoglycaemia } & \\ 1 \text { (very important) } & 182(28) & 0.50 \\ 2 & 182(28) & 0.27 \\ 3 & 148(23) & 0.32 \\ 4 & 88(14) & 0.14 \\ 5 & 26(4) & 0.12 \\ 6 \text { (totally unimportant) } & 13(2) & 0.08 \\ \text { Measuring blood glucose as rarely as possible } & \\ 1 \text { (very important) } & 107 & 0.38 \\ 2 & 115 & 0.40 \\ 3 & 112 & 0.45 \\ 4 & 160 & 0.13 \\ 5 & 68 & 0.34 \\ 6 \text { (totally unimportant) } & 77 & 0.22\end{array}$

${ }^{\text {a }} \mathrm{SH}=$ severe hypoglycaemia treated with glucagon or glucose injection

Additionally, we tested six composite scores by grouping the variables as listed in Tables 1-5: 1) history of hypoglycaemia; 2) clinical characteristics or disorders possibly predisposing to hypoglycaemia; 3 ) diabetes management related factors possibly predisposing to hypoglycaemia; 4) hypoglycaemia awareness; 5) treatment goals that could predispose to hypoglycaemia; 6) patient behaviour, attitudes or misconceptions that could predispose to hypoglycaemia. The inclusion of these scores, however, did not yield better results than the single variables listed above. From these 33 variables 5 were predictors of SH: 1) $\mathrm{SH}$ (necessitating assistance) during the preceding 12 months, 2) any previous event of SH (necessitating assistance), 3) C-peptide negativity, 4) social class, and 5) patients' determination to reach blood glucose values less than $7.8 \mathrm{mmol} / \mathrm{l}$, indicating that the lower the social status and the higher the patients' determination to reach normoglycaemia, the higher the risk of SH. The results of the corresponding Cox model (model I) are shown in Table 6. In a second analysis all variables describing the history of hypoglycaemia were excluded. In place of the variables $\mathrm{SH}$ during the preceding 12 months and any history of SH the variables hypoglycaemia awareness (the more impaired the higher the risk) and patients' inappropriate denial of $\mathrm{SH}$ as their particular problem became predictors of $\mathrm{SH}$. The results of the corresponding 
Table 6. Results of final Cox proportional hazards model including history of SH (model I, $n=627$ )

\begin{tabular}{|c|c|c|c|c|c|c|}
\hline Variables & $\begin{array}{l}\text { Regression } \\
\text { coefficient }\end{array}$ & $\begin{array}{l}\text { Standard } \\
\text { error }\end{array}$ & $p$-value & Unit for HR & HR & $95 \% \mathrm{CI}$ \\
\hline $\begin{array}{l}\text { SH necessitating assistance during preceding } \\
12 \text { months }\end{array}$ & 1.006 & 0.225 & 0.0001 & yes/no & 2.73 & $1.76-4.25$ \\
\hline Blood glucose targets $<7.8 \mathrm{mmol} / \mathrm{l}$ & -0.387 & 0.127 & 0.0023 & $1^{\mathrm{a}}$ & 0.68 & $0.53-0.87$ \\
\hline Social status & -0.050 & 0.021 & 0.0162 & $5^{\mathrm{b}}$ & 0.78 & $0.63-0.96$ \\
\hline C-peptide negativity & 1.379 & 0.594 & 0.0202 & yes/no & 3.97 & $1.24-12.71$ \\
\hline Any history of SH necessitating assistance & 0.639 & 0.293 & 0.0289 & yes/no & 1.89 & $1.07-3.36$ \\
\hline Explained variation & $\begin{array}{l}\text { Entropy } R^{2} \\
\text { Likelihood ratio } R^{2}\end{array}$ & $\begin{array}{l}=6.7 \% \\
=10.4 \%\end{array}$ & & & & \\
\hline
\end{tabular}

$\mathrm{HR}=$ hazard ratio, $\mathrm{CI}=$ confidence interval

${ }^{a}$ value range 1 (very important) to 6 (totally unimportant)

${ }^{\mathrm{b}}$ value range 0 (lowest social level) to 24 (highest social level)

Table 7. Results of final Cox proportional hazards model excluding history of SH (model II, $n=625$ )

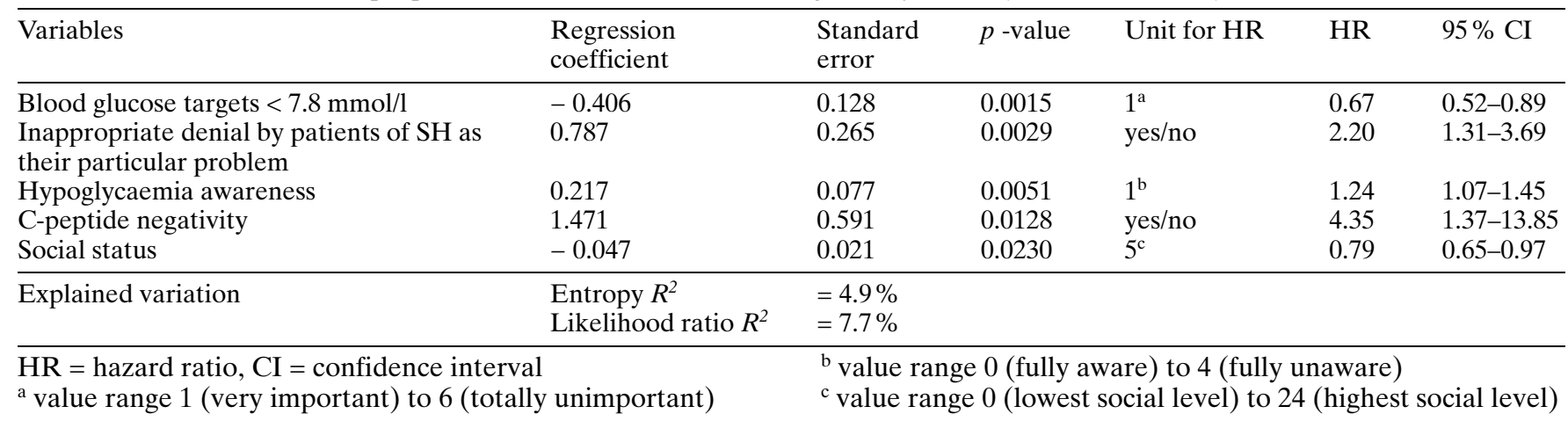

Cox model (model II) are shown in Table 7.The plots of the log of the negative log of the estimated survival functions against log time and the inclusion of timedependent covariates showed no clear violations of the proportional hazards' assumption in both models. An exception was C-peptide negativity, where the hazards did not seem parallel. However, since nearly all observations ( $97 \%$ ) of the group positive for Cpeptide were censored, the proportional hazards' assumption could not be assessed adequately and it was impossible to find a model showing a clear better fit. When a stratified Cox model was applied with $\mathrm{C}$-peptide negativity as stratum variable, the results for the other risk factors were nearly the same as before. Hence, only the results of the standard Cox proportional hazards models as described above are given. The results for the estimated values of variation explained by the covariates are shown in Tables 6 and 7. Estimated failure probabilities for different sets of covariate values based upon model I are given in Table 8.

\section{Discussion}

This study is the first comprehensive evaluation of risk factors of hypoglycaemia in a population based cohort of adults with Type I diabetes. The study group comprised a large number of subjects with a $98 \%$ complete follow-up after a mean time of 19 months. Of these patients with a mean diabetes duration of almost 20 years $61 \%$ had a history of SH necessitating assistance and $48 \%$ reported treatment with glucagon or glucose injection on at least one occasion. Applying the more restricted definition of $\mathrm{SH}$, the incidence for the preceding year as assessed retrospectively at baseline and at follow-up was almost identical ( 0.21 cases per patient year and 0.20 cases per patient year, respectively). This observation indicates validity of the evaluation protocol used in this study.

Only a few items evolved as risk predictors: $\mathrm{SH}$ necessitating assistance during the preceding 12 months, any history of SH necessitating assistance, C-peptide-negativity, patients' determination to reach normoglycaemia, and social status. Only after eliminating all variables of previous events of hypoglycaemia from the statistical models two further risk factors emerged, the denial of an existing hypoglycaemia problem and impaired awareness of hypoglycaemia.

Residual beta-cell function has recently been found to be protective against $\mathrm{SH}$ in two large clinical trials of intensified insulin treatment $[2,3]-$ a finding confirmed in this population based study. Compared to other risk factors the relative risk of about 4 caused 
Table 8. Estimated risks for SH after 12 months (failure probabilities) based upon Cox model I

\begin{tabular}{|c|c|c|c|c|}
\hline Variable & $\begin{array}{l}\text { Worst } \\
\text { possible }^{a}\end{array}$ & $\begin{array}{l}\text { Best } \\
\text { possible }^{a}\end{array}$ & $\begin{array}{l}\text { Worst } \\
\text { observed }^{\mathrm{a}}\end{array}$ & $\begin{array}{l}\text { Best } \\
\text { observed }^{\mathrm{a}}\end{array}$ \\
\hline SH necessitating assistance during preceding 12 months & yes & no & yes & no \\
\hline Blood glucose targets $<7.8 \mathrm{mmol} / \mathrm{l}^{\mathrm{b}}$ & 1 & 6 & 1 & 6 \\
\hline Social status $\mathrm{c}$ & 0 & 24 & 1 & 4 \\
\hline C-peptide negativity & yes & no & yes & no \\
\hline Any history of SH necessitating assistance & yes & no & yes & no \\
\hline Risk & 0.539 & 0.002 & 0.521 & 0.004 \\
\hline $95 \% \mathrm{CI}$ & $0.293-0.799$ & $0.000-0.004$ & $0.297-0.674$ & $0.000-0.012$ \\
\hline
\end{tabular}

${ }^{a}$ with respect to the risk of $\mathrm{SH}$

${ }^{\mathrm{b}}$ value range 1 (very important) to 6 (totally unimportant)

${ }^{\mathrm{c}}$ value range 0 (lowest social level) to 24 (highest social level)

by C-peptide-negativity was exceptionally high. This observation calls for particular efforts to preserve beta-cell function in Type I diabetic patients - even though the mechanism of the C-peptide related protection against $\mathrm{SH}$ is not known.

In an accompanying paper, we have described the impact of the patients' social status on the overall quality of diabetes care in this study group [11]. There was a substantial social class gradient concerning various items of disease-management, namely that more often high social class patients had participated in a DTTP, had specialized out-patient care, used intensified insulin treatment regimens, carried out blood glucose self-monitoring more often and more self-adaptations of insulin dosages on a day-to-day basis. These disease-management related factors are considered prerequisites to recognize early, treat and, most importantly, prevent SH.

The more important it was for the patients to achieve blood glucose values of consistently less than $7.8 \mathrm{mmol} / \mathrm{l}$, the higher was their risk of SH. This result corresponds with recent data from the DCCT [2]. Even after adjustment for the current $\mathrm{HbA}_{1 \mathrm{c}}$ level, in the DCCT intensive treatment was still associated with a significantly increased risk of hypoglycaemia suggesting that a substantial portion of the increased risk associated with intensive therapy was related to the pursuit of normoglycaemia, independent of the $\mathrm{HbA}_{1 \mathrm{c}}$ level actually achieved.

The inappropriate denial by patients of $\mathrm{SH}$ as their particular problem evolved as a further risk factor of $\mathrm{SH}$ in this study. This risk was as strong a predictor of $\mathrm{SH}$ as impaired awareness of hypoglycaemia. Both of these factors were not independent of previous events of SH. This is in accordance with the assumptions that hypoglycaemia may induce impairment of hypoglycaemia awareness [22-24] and that this, in turn, could predispose to SH [14, 7]. Repeated hypoglycaemia, however, could also be the result of inappropriate insulin treatment strategies, a lack of patient training or careless patient behaviour. In a previous study we have shown that participation of patients in a structured 5-day group treatment and teaching programme for intensification of insulin therapy leads to a decrease in $\mathrm{HbA}_{1 \mathrm{c}}$ levels and a decrease in the risk of $\mathrm{SH}[3,25]$.

In the DCCT by the end of the study after an average of 6.5 years $65 \%$ of the patients in the intensive treatment group had had at least one episode of SH requiring assistance. In the present study $15 \%$ of patients had at least one episode of SH treated with glucagon injection or intravenous glucose after a mean of 19 months of follow-up. These differences in the percentages of patients with episodes of $\mathrm{SH}$ and in follow-up periods have to be taken into account when comparing data concerning the explained variance of $\mathrm{SH}$ between these two studies. In the present study, the hazard ratios showed a considerable impact of the identified risk factors on the risk of hypoglycaemia, especially SH during the preceding year and Cpeptide negativity. In terms of failure probabilities within 12 months a patient with the worst possible set of covariate values (i.e. a C-peptide negative patient of the lowest social class with a previous event of $\mathrm{SH}$ and, in addition, $\mathrm{SH}$ during the preceding 12 months who expressed the highest possible determination for a target blood glucose value $<7.8 \mathrm{mmol} / \mathrm{l}$ ) had an estimated risk of 0.54 , whereas a patient with the best possible set of covariate values had only an estimated risk of 0.002 (Table 8). In fact, the patient with the worst observed profile of covariate values had an estimated risk of 0.52 and the patient with the best observed set of covariate values had an estimated risk of 0.004 (Table 8). Actually, neither the worst nor the best patient had any event of SH after 10 and 18 months of observation, respectively. Although the hazard ratios and the differences of failure probabilities for different sets of covariate values showed a high impact of the risk factors on the risk of hypoglycaemia, the estimated values of explained variation were low. Considering that $R^{2}$ values in survival time studies typically range between 10 and $45 \%$ [26], the values of the explained variation of both Cox models were low (between 5 and $10 \%$, depending on the model and the type of measure used). Hence, in this study the covariates were not able to improve individual predictions 
considerably because at the end of follow-up $85 \%$ of the patients were still event-free. Using the naive prediction that a patient has no hypoglycaemia - regardless of the covariate values - would yield an error rate of less than $15 \%$. This result can only be improved slightly by using the covariate values for prediction. Nevertheless, the covariates have a high impact on the risk of hypoglycaemia. After 12 months a patient with the worst possible set of covariate values had a more than 300-fold increase of risk compared with a patient with the best possible set of covariate values.

In conclusion, the present study shows that in a population-based representative group of adult patients with Type I diabetes a history of SH, C-peptide negativity, social class, and patients' determination to reach normoglycaemia are important predictors of $\mathrm{SH}$.

Acknowledgements. This study has been funded by a grant of the Public Health Research Group of Northrhine-Westfalia (project II-C7). We acknowledge the excellent co-operation with the participating family physicians; G. Paletta, study secretary, J. Brötz, data documentation, D. Hemmann, S. Glück, Dr. T. Heise, Dr. E. Lipka, C. Molina-de-Schneider, Dr. A. Trocha, Dr. E. Wessel, Dr. Ch. Weyer, Dr. R. Windecker, and Dr. S. Geyer, Heinrich-Heine Universität Düsseldorf; Dr. H.-G. Huber and Prof. Dr. J.-D. Hoppe, physicians' chamber of Northrhine; Boehringer-Mannheim (Mannheim, Deutschland) for providing the mobile examination van; Hoechst-Marion-Roussel (Frankfurt, Deutschland) for financial support of the follow-up study; Peter-Klöckner Stiftung (Duisburg) for generous financial support (grants to Prof. M. Berger).

Contributors: I. Mühlhauser was the principal investigator and author of this paper, responsible for inception and design, organisation and carrying-out of the study, and its data preparation. H. Overmann has contributed to the preparation of the evaluation protocols, organisation of the study and was the principal investigator responsible for data collection. R. Bender, as statistician, was involved in the planning of the study, and was responsible for analysis and interpretation of the data. U.Bott was the principal investigator of the quality of life parameters. M.Berger was co-principal investigator involved in planning and organisation of the study, data interpretation and writing of the manuscript.

\section{Appendix}

Calculation of Failure Probabilities.

Based on the Cox regression model [15] individual failure probabilities can be calculated as 1-S $(t \mid x)$, where $\mathrm{S}(t \mid x)=\mathrm{S}_{0}(t)^{\exp \left(\beta^{\prime} \mathrm{x}\right)}$ is the conditional survival probability at time $t$ for an individual with covariate values $x, \beta$ is the vector of regression coefficients, and $\mathrm{S}_{0}(t)$ is the baseline survival function. As the baseline survival function is estimated nonparametrically no closed formula for calculation of failure probabilities is available. Considering model I (Table 6) and the time $t=12$ months one can calculate failure probabilities for different sets of covariate values as follows. Let $\mathrm{X}_{1}=\mathrm{SH}$ during preceding 12 months, $\mathrm{X}_{2}=$ determination for a target blood glucose value less than $7.8 \mathrm{mmol} / 1, \mathrm{X}_{3}=$ social status, $\mathrm{X}_{4}=\mathrm{C}$-peptide negativity, and $\mathrm{X}_{5}=$ any history of $\mathrm{SH}, \mathrm{S}_{0}(12)=0.946$, and the regression coefficients from Table 6:
Risk of hypoglycaemia within

12 months $=1-0.946^{\exp \left(1.006 \mathrm{X}_{1}-0.387 \mathrm{X}_{2}-0.05 \mathrm{X}_{3}+1.379 \mathrm{X}_{4}+0.639 \mathrm{X}_{5}\right)}$

Example: For the covariate values

$\mathrm{X}_{1}=1, \mathrm{X}_{2}=1, \mathrm{X}_{3}=0, \mathrm{X}_{4}=1, \mathrm{X}_{5}=1$

Risk $=1-0.946^{\exp (2.637)}=0.539($ Table 8$)$.

Note that this equation only holds for $t=12$. Other time points would require the values of the baseline survival function at these time points.

\section{References}

1. The Diabetes Control and Complications Trial Research Group (1991) Epidemiology of severe hypoglycaemia in the Diabetes Control and Complications Trial. Am J Med 90: 450-459

2. The Diabetes Control and Complications Trial Research Group (1997) Hypoglycemia in the Diabetes Control and Complications Trial. Diabetes 46: 271-286

3. Bott S, Bott U, Berger M, Mühlhauser I (1997) Intensified insulin therapy and the risk of severe hypoglycaemia. Diabetologia 40: 926-932

4. Pramming S, Thorsteinsson B, Bendtson I, Binder C (1991) Symptomatic hypoglycaemia in 411 type 1 diabetic patients. Diabet Med 8: 817-822

5. Hepburn DA, Patrick AW, Eadington DW, Ewing DJ, Frier BM (1990) Unawareness of hypoglycaemia in insulin-treated diabetic patients: prevalence and relationship to autonomic neuropathy. Diabet Med 7: 711-717

6. White NH, Skor DA, Cryer PE, Levandoski LA, Bier DM, Santiago JV (1993) Identification of type 1 diabetic patients at risk for hypoglycemia during intensive therapy. $\mathrm{N}$ Engl J Med 308: 485-491

7. Clarke WL, Cox DJ, Gonder-Frederick LA, Julian D, Schlundt D, Polonsky W (1995) Reduced awareness of hypoglycemia in adults with IDDM. Diabetes Care 18: $517-522$

8. Mühlhauser I, Toth G, Sawicki PT, Berger M (1991) Severe hypoglycemia in Type 1 diabetic patients with impaired kidney function. Diabetes Care 14: 344-346

9. Kimmerle R, Heinemann L, Delecki A, Berger M (1992) Severe hypoglycemia incidence and predisposing factors in 85 pregnancies of Type I diabetic women. Diabetes Care 15: 1034-1037

10. Gonder-Frederick L, Cox D, Kovatchev B, Schlundt D, Clarke W (1997) A biopsychobehavioral model of risk of severe hypoglycemia. Diabetes Care 20: 661-669

11. Mühlhauser I, Overmann H, Bender R, Bott U, Jörgens V, Trautner C, Siegrist J, Berger M (1998) Social status and the quality of care for adult people with Type 1 diabetes - a population based study. Diabetologia, 41: 11391150

12. Mühlhauser I, Overmann H, Bott U, Jörgens V, Berger M (1996) Erfassung der Versorgungsqualität von erwachsenen Personen mit Typ-I-Diabetes im Ärztekammerbereich Nordrhein. In: Berger M, Trautner C (eds) Die Forderungen von St. Vincent - Stand 1996 in Deutschland, Kirchheim-Verlag, Mainz, pp 97-104

13. Bott U, Mühlhauser I, Overmann H, Berger M (1998) Validation of a diabetes-specific quality of life scale for patients with Type 1 diabetes. Diabetes Care 21: 757-769

14. Gold AE, MacLeod KM, Frier BM (1994) Frequency of severe hypoglycemia in patients with Type I diabetes with 
impaired awareness of hypoglycemia. Diabetes Care 17: 697-703

15. Cox DR (1972) Regression models and life-tables. Journal of the Royal Statistical Society (B) 34: 187-220

16. Theil H (1970) On the estimation of relationships involving qualitative variables. Am J Sociol 76: 103-154

17. Schemper M (1990) The explained variation in proportional hazards regression. Biometrika 77: 216-218. Correction: Biometrika (1994) 81: 631

18. Madalla GS (1983) Limited-dependent and qualitative variables in econometrics. Cambridge University Press, Cambridge, UK

19. Magee L (1990) $R^{2}$ measures based on Wald and likelhood ratio joint significance tests. Am Statistician 44: 250-253

20. Schemper M. (1992) Further results on the explained variation in proportional hazards regression. Biometrika 79: 202-204

21. SAS (1991) SAS Technical Report P-217, SAS/STAT Software: the PHREG Procedure, Version 6. SAS Institute, Inc., Cary, NC
22. Rattarasarn C, Dagogo-Jack S, Zachwieja J J, Cryer P E (1994) Hypoglycemia-induced autonomic failure in IDDM is specific for stimulus of hypoglycemia and is not attributable to prior autonomic activation. Diabetes 43: 809-818

23. Fanelli C, Pampanelli S, Epifano L et al. (1994) Long-term recovery from unawareness, deficient counterregulation and lack of cognitive dysfunction during hypoglycaemia, following institution of rational, intensive insulin therapy in IDDM. Diabetologia 37: 1265-1276

24. Amiel S (1994) R.D. Lawrence Lecture 1994. Limits of normality: The mechanisms of hypoglycaemia unawareness. Diabet Med 11: 918-924

25. Jörgens V, Grüsser M, Bott U, Mühlhauser I, Berger M (1993) Effective and safe translation of intensified insulin therapy to general internal medicine departments. Diabetologia 36: 99-105

26. Schemper M, Stare J (1996) Explained variation in survival analysis. Stat Med 15: 1999-2012 